\title{
A Study on the Life Cycle Cost of Green Buildings in Shaanxi
}

\author{
Zhang Fan \\ School of Architecture and engineering of Yan'an University, Yan'an, 716000, China
}

Keywords: green building, the whole life cycle, cost analysis

Abstract: The implementation of sustainable development strategies, such as energy conservation and emission reduction, has become target for various countries, and the promotion of green buildings is one of the ways to achieve sustainable development. In such an environment, green building will become a mainstream trend of future development. However, the cost of green buildings is higher than that of ordinary buildings, which is a major constraint for their extensive development and application. Based on the principle of life cycle cost minimization, this paper briefly introduces and analyzes the green building evaluation system based on life cycle cost.

\section{Life Cycle Theory of Green Buildings}

Since the 1960s, with the introduction of the concept of green building, green building has been gradually applied to practice, and gradually developed and formed a better design method and evaluation system. During the 12th five-year plan period, Shaanxi province successfully completed all the targets and tasks, effectively increasing the contribution rate of energy conservation and emission reduction, forming an energy saving capacity of 966 thousand tons of standard coal annually, and saving cultivated land 2. 580,000 mu, reducing of carbon dioxide 2.54 million tons. The whole life cycle process refers to a design theory that takes into account all the links of the product life process in the design stage and allows all relevant factors to be comprehensively planned and optimized in the product design stage.

\section{Life Cycle Cost Analysis of Green Buildings}

The full life cycle cost of green buildings refers to a series of costs incurred in the early decision-making, design, bidding, bidding, construction, project acceptance and demolition of buildings, including the r\&d cost of buildings, the installation cost of equipment, the operation and maintenance cost of later stage and the demolition and settlement cost. According to the cost of construction stage, the life cycle cost of green building includes four major parts: the decision-making and design cost of the project, the construction cost, the use and maintenance cost, and the recovery and treatment cost. 


\subsection{The decision-making and design cost of green buildings}

The decision-making and design cost of green building includes the proposal of the project proposal, the selection of the project site, the expenses incurred during the exploration and research. The preparation of the green building decision design stage has considerable impact on the building as a whole, not only affecting the later use of the building, but also affecting the cost and economic benefit of the green building during the construction process, and saving funds for the whole project if the decision design stage is ready for improvement.

\subsection{The construction cost of green buildings}

The construction cost of green building refers to all expenses incurred in the construction process, including the purchase cost of materials, the purchase cost of construction equipment, the labor wage, the management cost and other costs. The construction process is the most important stage of green building, which affects the quality of construction projects in essence. The cost of construction is also the highest.

\subsection{The cost of using and maintaining green buildings}

The use and maintenance cost of green buildings refers to the human, material and financial resources that residents need to pay in the later use process of green buildings, including equipment maintenance cost and energy consumption cost of buildings. Generally, the life cycle of green buildings is relatively long, and the use and maintenance cost of green buildings accounts for a large proportion of the whole life cycle cost.

\subsection{Recycling and treatment costs of green buildings}

When a green building reaches its useful life, it needs to dispose of its waste materials. The cost incurred in this process is the recycling cost of the green building. Different disposal methods of waste materials have different impacts on the environment and society, and their costs are also different.

\section{Cost control by stages}

\subsection{Decision-making stage}

(1) Size, resources and location of the project

To investigate the social needs of the project and economic and social benefits to determine the size of the project; To investigate and analyze the relevant resources, and to determine the necessity of the project.

(2) Environmental and energy status of the project

According to the characteristics of the project, the environmental impact status of the project are considered, the target value of indoor air quality of the project and the sound insulation effect of the project are determined, and the environmental impact assessment report of the project is made.

(3) To provide alternative plans for the project 


\subsection{Design stage}

\subsubsection{To fully perform the feasibility study}

According to the bottom line of the investment limit, all construction units and design units are required to optimize the design scheme as much as possible. After the investment decision is made, the investment will be saved and the project cost will be reduced.

\subsubsection{To strengthen technical and economic analysis of the actual stage}

The optimization choice of the design scheme is not only from the perspective of technology, but more importantly from the background of combining technology with economy. On the premise of satisfying the engineering structure and using function, the design scheme is selected according to economic indicators and comprehensive benefits, so that the innovation of cost control can obtain due attention and recognition.

\subsubsection{To build a database of building types}

In order to improve the design scheme and achieve cost control at the source, the design unit should establish a complete set of cost database of various building types, including collecting external data and sorting out existing data, which is not only convenient for designers to inquire and select, but also can truly realize cost saving.

\subsubsection{To adopt limit design}

The limited design is to control the preliminary design according to the approved feasibility study report and investment estimate. It controls the technical design according to the approved general budget of the preliminary design, and then controls the construction drawing design based on the estimated budget of the technical design.

\subsection{Construction stage}

The green construction stage includes site protection, environmental impact control, materials and resources, energy saving and water saving, personnel safety and health, etc. It should not only satisfy construction need but also comply with the green construction principle. The green construction, based on the traditional construction, is not totally independent of the traditional construction construction system, innovates and elevates the traditional construction system according to the scientific concept of development.

\subsection{Operation and maintenance stage}

The maintainability of the project refers to the maintenance during operation of the project, the ease of maintenance, the cost of maintenance during operation, the degree of difficulty in handling the interface of the project and the new technology, the difficulty of interface handling, and the interface treatment cost status. Only when the project maintenance is simple and the cost is low, the project will have vitality and development prospects.

\section{Conclusion}

After entering the operation and maintenance stage, the project has been completed, and the key to reducing the whole life cycle cost is to formulate a reasonable operation and maintenance plan, 
which is divided into long-term plan and short-term plan. The operation and maintenance plan should be designed with the minimum life cycle cost, and the overall cost of the operation and maintenance facilities should be reduced according to the contract by formulating a reasonable operation and maintenance plan. Secondly, in order to reduce the negative impact of the environment, it has to change all the criteria, the operating protocols and other documents to design and manage these facilities, to ensure that the standard of these modifications is carried out, and a full training program can be implemented.

\section{Acknowledgments}

Fund project: university-level research project of Yan’an University (YDQ2017-23).

\section{References}

[1] Liu Lingling. On the significance of green building economy [J]. China foreign capital, 2012,28 (5): $156-159$.

[2] Wang Huiying. Discussion on the evaluation and improvement of the current situation of green building economy [J]. Ningxia: Ningxia Haiyuan county housing and urban-rural construction bureau. Chinese and foreign entrepreneurs, 201, 26(12): 11-16.

[3] Wu Fei. On the current situation and analysis of China's green building economy [J]. Gansu science and technology. 2013,15:131-132.

[4] Huang Rubao. Architectural economics [M]. Tongji university press, 2010 (2).

[5] Bai Huiying. Current situation and analysis of China's green building economy [J]. Building materials and decoration.2014:254-255.

[6] Kang Zhongqiang. Discussion on the development of China's green building economy [J]. 2013(2):134.

[7] Zhao chaoxia. Research on countermeasures for sustainable development of China's green building economy. [J] Gansu science and technology.2014(30):96-97.

[8] Sun Gojing. A brief discussion on the development prospect of green building economy. [J] technical discussion. 2015(2) 